\title{
Britain's National Health Service Revisited
}

\author{
Rudolf Klein
}

Britain's National Health Service (NHS) presents a paradox. It is the only health care system in the rich world that is actively and enthusiastically committed to spending more money instead of seeking to restrain cost increases. Extra tax billions are being pumped into the service by the government at an unprecedented rate. In fiscal year 2002-2003, the budget of the NHS rose by more than 10 percent as part of a long-term fiscal strategy announced by Prime Minister Tony Blair four years ago. The aim of the increases is to bring spending on health care up to the European Union's average of 8 percent of the gross domestic product. At the same time, an ambitious process of self-transformation is under way. Founded in 1948 as a technocratic, paternalistic service, with scarce resources allocated according to medical and bureaucratic criteria of need, the NHS is now being redesigned as a consumer-oriented service.

Despite the additional money flowing into the system and despite the enticing vision of a service that combines health care that is universal, comprehensive, and free at the point of delivery with choice, flexibility, and responsiveness, controversy and discontent still dog the NHS. The medical profession has diagnosed itself as suffering from poor morale. The public remains skeptical. In a recent poll, 69 percent of those interviewed said they believe that the government is not improving the NHS. ${ }^{1}$ In this article, I explore this paradox and ask why increased funding has so far failed to increase satisfaction or stability. The focus is on the NHS in England. Wales and Scotland have followed somewhat divergent paths since being granted a degree of self-government, which allows them some freedom in determining their own health care policies.

The paradox is all the more puzzling because there is considerable evidence that more money has indeed meant better services. The government's report on progress as of April 2003 claims substantial improvements. ${ }^{2}$ Since 2001, an additional 17,000 nurses, 2000 therapists, 1200 consultants, and 400 general practitioners have been recruited. New medical schools are being launched to train more doctors. A new style of diagnosis-and-treatment centers, designed to provide quick day surgery, are being opened. Services for patients who have coronary heart disease are being modernized and expanded. Long waiting times, which have been the NHS's most notorious failing, are declining. So, for example, the number of people who had to wait for more than a year for an operation fell by 68 percent during the past year, from 29,600 to 9600 .

Some of these claims, however, are self-serving and suspect. For example, the increases in the numbers of doctors, nurses, and other workers do not take into account whether their positions are fulltime or part-time. Nor has the government's credibility been helped by the revelation that some hospitals have fiddled their waiting-time figures in order to meet the target set by the Department of Health. An independent audit by the Commission for Health Improvement, the NHS's inspectorate, confirmed that there has been both progress and cause for skepticism. The commission reported that although the NHS "as a whole is getting better," progress had been "patchy and inconsistent," and "the improvement in NHS services is not yet affecting frontline delivery of services on a large enough scale to impact on most members of the public." 3

In short, public perceptions lag behind the achievement of results. The difficulties that some patients continue to face in getting an early appointment with their general practitioners and the long hours some have to wait in emergency departments on occasion have more resonance than national data on improvements in performance. The individual experience of shortcomings trumps the statistical evidence. And changes for the better in the quality of care - for example, the accelerating use of statins - lack public visibility. Moreover, the media highlight the failings of the NHS, not its successes. 
Achievement, in turn, lags behind expectations. Almost as soon as the Labour government came into office in 1997, it committed itself to creating "a modern and dependable health service fit for the twenty-first century." 4 There followed a succession of policy documents the rhetorical exuberance of which served to crank up expectations even further. The anxiety of ministers to translate their ambitions and money into visible improvements - that is, to achieve a political return on the extra costs of the NHS - has been reflected in a series of initiatives and policy changes that, perversely, have created turmoil and a sense of overload in the service. The NHS is now suffering from an acute case of "change fatigue." The twists and turns of public policy that have marked the past six years are examined here to explain the paradox noted at the beginning.

A CHANGING SCENE

To understand what is happening now, it is necessary to look back at the reforms introduced by the Conservative government in 1991 - that is, the introduction of the so-called internal market. Before 1991, hospitals and other medical services (apart from primary care) were directly funded and managed by local Health Authorities, which acted as agents of the Department of Health. After the changes were introduced, the Health Authorities became purchasers that were responsible for contracting for the care of their populations, and the providers of care were organized as trusts. The trusts were semi-independent bodies that were responsible for managing their own budgets, which were to be determined (in theory, at least) not by bureaucratic decisions from above but by their own ability to attract business from the purchasers, although ultimately they remained accountable to the secretary of state for health. In addition, general practitioners were given the option of becoming fund-holders - that is, holders of their own budgets - in order to contract for a limited range of secondary services for their patients. If the general practitioners chose not to become fund-holders, the Health Authorities would continue to contract for secondary care from the provider trusts on their behalf. In the event, the Health Authorities remained the dominant purchasers.

The notion driving these changes was that competition among providers to secure contracts either from the Health Authorities or from general practitioners who chose to be fund-holders would im- prove efficiency and responsiveness. For a variety of reasons, among them the reluctance of the government to give free rein to market forces, the reforms never functioned as intended. ${ }^{5,6}$ There never was much competition. However, the 1991 reforms meant that the NHS inherited by the Labour government in 1997 had a very different institutional landscape from that of its original design in 1948.

The modernization project introduced by the Labour government in 1997 was characterized by three features. ${ }^{7}$ First, it repudiated, at least rhetorically, the Conservative internal-market model. Competition was to be replaced by cooperation. The change was largely semantic. The division between the purchasers of health care (renamed commissioners) and the providers (hospital and community trusts) was retained. The main effect was to replace a one-year contract with longer contracts, usually for three years.

Second, the Conservative scheme for fundholding general practitioners was abolished, although it was reincarnated in Primary Care Trusts. In contrast to fund-holding, participation in the Primary Care Trusts was compulsory - all general practitioners, dentists, pharmacists, and other providers of primary care within a given geographic area were required to enroll. These new Primary Care Trusts were given independent budgets and were made responsible for commissioning health care on behalf of their populations, which averaged 100,000 persons, thus making the Health Authorities redundant. The Primary Care Trusts now control 75 percent of the total NHS expenditure.

Third, there was considerable emphasis on achieving the NHS's original aim of providing services of a uniformly high quality throughout the country. The NHS that the Labour government inherited remained marked by large geographic variations in the level and quality of the services available. Accordingly, there was to be a drive to standardize services and monitor quality.

Inherent in this program was a tension. On the one hand, the emphasis on creating powerful Primary Care Trusts, or putting general practitioners in the driving seat, as the government put it, suggested a devolved service - power to the periphery, with decisions about what services to provide and how to configure them left at the local level. On the other hand, the stress on national standards suggested a centralized service, with decisions about the level and configuration of services made at the center. Furthermore, the program left a policy vac- 
uum. Once the idea of relying on market discipline was abandoned, what remained was the question of the kind of incentives that could be devised to reward efficiency or conformity with government policy. The history of the NHS since 1997 is, in effect, a record of attempts to resolve this tension and to fill the policy vacuum.

In the first five years or so of the Labour government's term in office, the tension was effectively resolved by ignoring the logic of creating the Primary Care Trusts. This was emphatically a period of centralization. The NHS, as it was designed in 1948, has been categorized as a command-andcontrol model of organizing health care. In practice, however, it never conformed to that model. The NHS would more accurately be described as an exhort-and-hope model, in which central government issued exhortations in the hope that the periphery would implement them - hence, the persistence of variations. But starting in 1997, the government did indeed construct a command-andcontrol model. In a succession of moves, the organizational structure of the NHS was reshaped to provide clear lines of accountability that run from the periphery to the center, thereby replacing a somewhat confused web of accountability. The National Institute of Clinical Excellence was created and charged with reviewing drugs, new forms of technology, and procedures and with issuing guidelines. The Commission for Health Improvement was set up to inspect trusts and report to the center. National Service Frameworks, blueprints of service configuration and practice, were issued.

Most important of all, perhaps, the government solved the problem of incentives by introducing performance targets for provider trusts. This was not an altogether new initiative. Performance indicators had been introduced in the NHS in the 1980s, but under the Labour government, the number of performance targets proliferated - to more than 300 by some counts, though ministers insist that the real figure is only 60 - and their use became central to the management of the NHS. The apotheosis of the target system is the annual star-rating exercise. Depending on their performance, provider trusts are awarded three, two, or no stars. For good performers, the prize is increased autonomy; for poor performers, the penalty is usually loss of office for the chief executive and being put under supervision by the Department of Health. The system for awarding stars is arcane. Put simply, however, stars are awarded on the basis of perfor- mance in five areas - the targets set by the Department of Health, most notably those for reducing waiting lists and times; clinical indicators; indicators of staff morale; indicators of how patients have been treated (a very mixed bag, partly based on national surveys of patients' satisfaction but also including data about patients' waiting times, the number of canceled operations, and the quality of food in hospitals); and scores assigned by inspectors from the Commission for Health Improvement.

Central management of the NHS created and reinforced a command-and-control system. From its inception, the NHS, because it is a tax-funded system, has drawn power to the center. The secretary of state for health is, in theory at least, accountable to Parliament for everything that happens in the NHS. Under the Labour government, however, the degree of central interference increased. Telephone calls from the secretary of state's office to exhort or censure chief executives of trusts became more frequent. From the prime minister down, there was a sense of frustration and impatience with the NHS. Many, but not all, trusts achieved their waiting-list targets. ${ }^{8}$ Why could not the good practices of some trusts in reducing waiting lists, improving the quality of patient care, providing quick service in emergency departments, and so on, be generalized?

The government did not rely on ministerial and managerial pressure exclusively. It also created the Modernization Agency, in effect the NHS's consultancy, whose missionaries are there to spread the gospel of good practice and to help trusts to improve their performance. Overall, the bombardment by targets and the nagging by ministers produced a climate of apprehension and sullen resentment in the NHS, and the reaction came. Early in 2003, the then secretary of state, Alan Milburn, announced his damascene conversion. ${ }^{9}$ In a speech, Milburn acknowledged that Labour's strategy of introducing "a plethora of service targets, inspection regimes, and national standards," although justified in order to attack the challenge of variations, had become counterproductive. He argued that "the NHS cannot survive as a monolithic topdown centralized system. Without greater diversity the NHS cannot be more responsive. Without responsiveness there cannot be public confidence. Without public confidence the NHS will not be sustainable." Milburn's speech not only marked the recognition that a command-and-control model may have perverse effects, but also reflected the realization that centralizing power means central- 
izing blame. That is, if the government claims that it can make waiting lists disappear, it will get the brickbats when the trick does not work.

The centerpiece of the new emphasis on localism was the announcement in 2002 of a plan to introduce "foundation trusts," ${ }^{10}$ which were conceived as having the freedom to decide on salary structures and levels for doctors and other staff (instead of being bound by national agreements) and to raise capital on the market (instead of being dependent on the Treasury). In response to strong opposition from within the Labour Party, however, these freedoms were severely circumscribed during the passage of the legislation through Parliament. One crucial distinction between the existing trusts and the new bodies remains. Whereas the governing bodies of the existing trusts are accountable to the secretary of state, those of the new bodies will be elected locally and will be accountable to an independent regulator. Initially, some 30 "three star" trusts will be selected for foundation status, but eventually all trusts, including Primary Care Trusts, are to graduate to the new, privileged foundation status. It is still too early to predict how the new system will work out, but, in theory, it represents a large step toward a health service that will be accountable to local communities, rather than to central government.

The invention of the foundation trusts is part of a larger shift toward a more pluralistic, consumeroriented health care system. "The NHS will move, over the next few years, from a monopoly provider of health services, run from Whitehall, to offer a greater diversity and plurality of services for NHS patients," according to the government. ${ }^{11}$ The 1997 rhetoric of putting general practitioners in the driver's seat has been replaced by the rhetoric of consumer choice. The government is committed to the principle of giving patients the right to choose their specialists and treatments by 2005 , starting with elective surgery. There are also to be changes in the system for directing funding to providers. A system of "payment by results" is gradually being phased in during the coming years, with the aim of supporting "patient choice by ensuring that diverse providers can be funded according to where the patients choose to be treated," in the words of the government document that announced the changes. ${ }^{11}$ Uniform national prices for specific interventions and conditions, which are first cousins of the diagnosis-related groups long used in the United States, are being introduced. The Primary
Care Trusts will commission the volume of activity required on the basis of this tariff, adjusted for case mix. If providers underperform, their funding will be reduced, though it is not clear what is to happen if providers overperform. Thus, patients' choices will not directly affect the flow of funds, except to the extent that they will influence the contracting policies of the Primary Care Trusts, a situation that may be a source of tension in the future.

Consumer choice includes the private sector. Traditionally, Labour has been hostile toward the private, fee-paying sector. But the present government has seen the private sector as a resource for overcoming the shortage of doctors, nurses, operating theaters, and so on, that has prevented the NHS from achieving ministerial goals. Whether NHS patients are treated in a public or a private hospital, the government has (rightly) argued, does not affect the equity principle, provided the treatment remains free of charge and according to need. In this, the government has followed the example of its Conservative predecessor. It has remained committed to the Private Finance Initiative, a system in which private contractors, drawing on market finance, build and maintain new hospitals, diagnostic treatment centers, and primary care facilities. Purchasers have been encouraged to contract with the private sector for specific services, mainly elective surgery - some NHS patients have even been sent to France and Germany for surgery.

At present, the scale of the private sector's involvement is modest. One crucial factor is that the surgeons and other clinicians working in the private sector are overwhelmingly NHS consultants. All NHS consultants have the right to choose a contract that allows them to engage part-time in private practice, and most do so. Income from private practice is a useful supplement to NHS salaries and can, in a few specialties at least, exceed them. Thus, if only at the margins, there is competition between the NHS and the private sector for the time of consultants. However, this competition is part of a wider problem, that of the relationship between the government and the medical profession.

DOCTORS AND THE STATE

As in the United States, the organized medical profession in Britain has largely lost the ability to influence, or to veto, major public policy decisions about the direction of change. ${ }^{12}$ Former Prime Minister Margaret Thatcher demonstrated the impotence of 
the medical profession in this respect when she introduced internal market reforms in the face of all-out opposition from the British Medical Association. The incoming Labour government's repudiation of the internal market pleased the profession but did not bear witness to its influence. Even though ministers sought and obtained endorsement of their strategy from leading medical figures, they did not involve the profession in the policymaking process. As in the United States, clinicians feel oppressed by what they see as managerial encroachments on their autonomy and as excessive demands for accountability that have flowed from the government's emphasis on quality control. They see themselves as overappraised and overinspected. Similarly, there is much resentment of the government's target system; this, clinicians claim, may often mean treating cases that can be quickly processed rather than treating medically urgent cases.

However, again as in the United States, the medical profession remains deeply involved in negotiations about pay, and there have been two important developments in this respect. First, a new contract for general practitioners has been agreed to. The aim of the contract is to link remuneration to the quality of practice and has been described by an American observer as "the boldest such proposal on this scale ever attempted anywhere in the world." ${ }^{13}$ Pay will be linked to 76 indicators of quality of various kinds - for instance, the quality of written records, recording of the blood pressure of 90 percent of patients annually, and the reduction of total or low-density lipoprotein cholesterol levels according to national guidelines. In return, general practitioners will have greater freedom to determine what services to provide as well as higher incomes. Equally important, they will be able to choose a salary option. One of the most important developments in recent years has been the growth in the number of general practitioners choosing to work not as small shopkeepers, with their income largely dependent on capitation payments, but as salaried employees in larger primary care teams that have contracts to deliver specific services. Some 30 percent of general practitioners now work under this scheme.

Second, a new contract for consultants is being introduced. Painfully negotiated by their leaders over a period of two years, the new contract was initially rejected in a ballot by consultants, even though it would have brought higher salaries. The sticking point was that the proposed contract would have given managers first call on the spare time of consultants and required them to work overtime when necessary. In short, as consultants saw it, the contract would have reinforced managerial control and threatened their ability to engage in private practice. Subsequently, the government yielded to pressure from the consultants, and a revised compromise contract was approved on a second ballot.

Apart from suspicions about the small print in any new contract, there are deep-seated anxieties about the changing role of consultants and the increased demands being made on them. In line with a European Union directive, the working hours of doctors in training - all those who have not achieved consultant status - are to be reduced from 72 hours a week initially to 58 and eventually to 48 hours a week. ${ }^{14}$ The new limit on hours means not only that the total number of doctors available to attend to patients at any one time will be reduced, exacerbating the NHS's shortage of medical staff, but also that consultants will have to take on responsibilities at night or on weekends that in the past had been left to their juniors. If there is discontent and low morale, the reasons for them are not to be found exclusively in the policies of the British government.

AN UNCERTAIN FUTURE

So far, Britain's experience suggests that it is almost as difficult to spend more money effectively in the NHS, at least in terms of generating any political dividends, as it is to control cost increases in the United States. Spending more money involves not only expanding the capacity of the service but also changing the dynamics of the system. Expanding capacity is difficult in the short term, even given a global recruitment drive to increase the number of doctors and nurses and recourse to the private sector. The problem for the government is one of timing - that is, whether or not the added staff and infrastructure needed to ensure that the NHS can deliver services of a higher quality and on a larger scale will be in place before the next election. A larger difficulty, however, is devising a structure and set of incentives that will ensure that the added resources are used efficiently and that the policy goal of making the NHS consumer-oriented is achieved.

The changes recently introduced - the repudiation of command and control, the creation of foundation trusts, and payment on the basis of results — promise much, but their effect will depend on 
how they are implemented. There are many uncertainties. The Primary Care Trusts will play a pivotal role, as purchasers of health care, in the emerging system, but whether they will have the managerial capacity to carry out this role is far from certain. Nor is it clear how much discretion the Primary Care Trusts will enjoy if their priorities do not match those of the central government. Again, it is not clear how far the purchasing decisions of the Primary Care Trusts will be driven by patients' choices or whether those decisions will constrain the choices of patients. Above all, to the extent that the rhetoric of consumer choice suggests that the NHS will be driven by demand, expectations may be raised that the service cannot satisfy. The NHS remains a budget-capped service; there is no open-ended commitment to meet patients' demands.

The real test of the government's strategy is to come. The present spending splurge is temporary, part of a five-year commitment by the government, and is unlikely to be sustained after 2007, when the commitment is due to end. Facing the prospect of a massive deficit, the government may be forced to make a painful political choice between cutting expenditures and raising taxes. Although demographic and technological pressures for more spending will persist, the NHS may have to accommodate to a return to low rates of budgetary growth. This will be a shock to the system, and it remains an open question whether the NHS will have changed sufficiently to cope with budgetary constriction and at the same time satisfy the expectations raised by the period of euphoric expansion.

From the London School of Hygiene and the London School of Economics, London.

1. Anyone see where the money's gone? Economist. May 8, 2003: 27-8.

2. Delivering the NHS plan - expenditure report. London: Department of Health, April 2003.

3. Getting better? A report on the NHS. London: Commission for Health Improvement, May 2003.

4. Secretary of State for Health. The new NHS: modern, dependable. London: Her Majesty's Stationery Office, December 1997.

5. Robinson R, Le Grand J, eds. Evaluating the NHS reforms. London: King's Fund Institute, 1993.

6. Enthoven AC. In pursuit of an improving National Health Service. London: Nuffield Trust, 1999.

7. Klein R. What's happening to Britain's National Health Service? N Engl J Med 2001;345:305-8.

8. Martin RM, Sterne JAC, Gunnell D, Ebrahim S, Davey Smith G, Frankel S. NHS waiting lists and evidence of national or local failure: analysis of health service data. BMJ 2003;326:188.

9. Localism: from rhetoric to reality. Speech given by the Rt Hon Alan Milburn MP, Secretary of State, to the new health network and the new local government network, 5 February 2003. London: Department of Health, 2003. (Accessed February 6, 2004, at http:// www.doh.gov.uk/speeches/milburnfeb03localism.htm.)

10. A guide to NHS foundation trusts. London: Department of Health, December 2002.

11. Reforming NHS financial flows: introducing payment by results. London: Department of Health, October 2002.

12. Laugesen MJ, Rice T. Is the doctor in? The evolving role of organized medicine in health policy. J Health Polit Policy Law 2003;28: 289-316.

13. Shekelle P. New contract for general practitioners. BMJ 2003; 326:457-8.

14. British Medical Association. Guidance on working patterns for junior doctors. London: Department of Health, November 2002.

Copyright (c) 2004 Massachusetts Medical Society. 